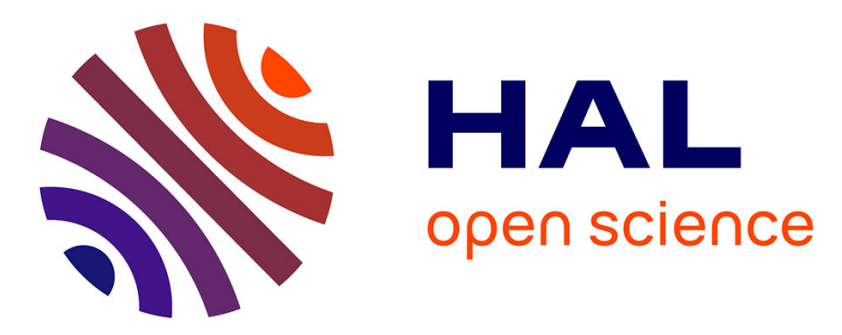

\title{
Using multi-frequency acoustic attenuation to monitor grain size and concentration of suspended sediment in rivers
}

\author{
S. A. Moore, Jérôme Le Coz, David Hurther
}

\section{- To cite this version:}

S. A. Moore, Jérôme Le Coz, David Hurther. Using multi-frequency acoustic attenuation to monitor grain size and concentration of suspended sediment in rivers. Journal of the Acoustical Society of America, 2013, 133 (4), pp.1959-1970. 10.1121/1.4792645 . hal-00841499

\author{
HAL Id: hal-00841499 \\ https://hal.science/hal-00841499
}

Submitted on 15 May 2020

HAL is a multi-disciplinary open access archive for the deposit and dissemination of scientific research documents, whether they are published or not. The documents may come from teaching and research institutions in France or abroad, or from public or private research centers.
L'archive ouverte pluridisciplinaire HAL, est destinée au dépôt et à la diffusion de documents scientifiques de niveau recherche, publiés ou non, émanant des établissements d'enseignement et de recherche français ou étrangers, des laboratoires publics ou privés. 


\section{Using multi-frequency acoustic attenuation to monitor grain size and concentration of suspended sediment in rivers}

Stephanie. A. Moore, ${ }^{*}$ Jérôme Le Coz, and André Paquier

Irstea UR HHLY Hydrology Hydraulics, 5 rue de la Doua CS70077, 69626

Villeurbanne cedex, France ${ }^{\dagger}$

David Hurther

Laboratoire des Ecoulements Géophysiques et Industriels, Domaine Universitaire BP 53, 38041 Grenoble, France

(Dated: April 5, 2013) 


\begin{abstract}
Multi-frequency acoustic backscatter profiles recorded with side-looking acoustic Doppler current profilers are used to monitor the concentration and size of sedimentary particles suspended in fluvial environments. Data at 300, 600 and $1200 \mathrm{kHz}$ are presented from the Isère River in France where the dominant particles in suspension are silt and clay sizes. The contribution of suspended sediment to the through-water attenuation was determined for three high concentration (> $100 \mathrm{mg} / \mathrm{L})$ events and compared to theoretical values for spherical particles having the size distributions that were measured by laser diffraction in water samples. Agreement was good for the $300 \mathrm{kHz}$ data, but it worsened with increasing frequency. A novel method for the determination of grain size using multi-frequency attenuation data is presented considering models for spherical and oblate spheroidal particles. When the resulting size estimates are used to convert sediment attenuation to concentration, the spheroidal model provides the best agreement with optical estimates of concentration, but the aspect ratio and grain size that provide the best fit differ between events. The acoustic estimates of size were one-third the values from laser grain sizing. This agreement is encouraging considering optical and acoustical instruments measure different parameters.
\end{abstract}

PACS numbers: $43.30 . \mathrm{Ft}, 43.20 . \mathrm{Fn}, 43.20 . \mathrm{Hq}, 43.30 . \mathrm{Pc}$

\footnotetext{
*moore@uottawa.ca

${ }^{\dagger}$ Now at: Department of Civil Engineering, University of Ottawa, 161 Louis Pasteur Pvt, Ottawa ON, K1N $6 \mathrm{~N} 5$, Canada
} 


\section{INTRODUCTION}

In recent years there has been an increased use of acoustic Doppler current profilers (ADCPs) to measure both flow speeds and sediment transport in rivers. Traversing a river with an downward-looking ADCP attached to a motor boat is an efficient and accurate manner in which to measure velocities throughout a river cross section since discharge values are typically within $5 \%$ of values measured with conventional methods such as current meters (Morlock, 1996; Oberg and Mueller, 2007). Side-looking ADCPs are being increasingly used to monitor flow speed in rivers (Morlock et al., 2002). They are typically installed on one river bank facing the other in order to measure a horizontal profile of velocity. If the bathymetry of the cross section is known, the velocity data can be combined with a record of the stage in order to obtain the discharge with use of the index-velocity method, among others (Hoitink et al., 2009; Le Coz et al., 2008; Morlock et al., 2002; Nihei and Kimizu, 2008).

ADCPs are composed of multiple monostatic piezo-electric transducers with operating frequencies typically between $300 \mathrm{kHz}$ and $2 \mathrm{MHz}$, depending on the instrument. In many rivers, the predominant scatterers at frequencies of $100 \mathrm{kHz}$ to $1 \mathrm{MHz}$ are suspended sediment. The amplitude of the backscattered intensity recorded by ADCPs can therefore be used to monitor the concentration of suspended sediment in the measurement volume (e.g. Gray and Gartner, 2009). The intensity of the backscattered signal depends on the concentration, mineral composition, shape and size of the suspended particles, with size and concentration being the two factors most likely to vary in space and time at a given site. Field and laboratory studies have demonstrated that the scattering from a suspension of natural sediments can be reasonably well modelled by assuming that the particles are spherical (Braithwaite, 1974; Hay, 1983). Empirical equations based on laboratory measurements have been developed to express the time-averaged backscattered intensity from a suspension of sand grains as a function of the non-dimensional wavelength, $k a$, where $k$ is the incident wavenumber and $a$ is the particle radius (Sheng and Hay, 1988; Thorne and Hanes, 2002; Thorne and Meral, 2008). For the range of particle sizes typically observed in the homo-

geneous suspension layer in rivers, $1 \mu \mathrm{m}<a<100 \mu \mathrm{m}$. For the range of frequencies of commercially available ADCPs $(300 \mathrm{kHz}-2 \mathrm{MHz}), k=1300-8400$ radians/m, therefore $k a<1$. For this range of $k a$ values, the backscattered intensity approximately depends on 
$a^{3}$ (Rayleigh, 1945); this means that sand particles $(d=2 a>64 \mu \mathrm{m})$ scatter significantly more sound than do silts or clays $(d<64 \mu \mathrm{m})$. In contrast, silts and clays dominate the attenuation (Urick, 1948). Topping et al. (2007) were the first to make use of this fact in their work on the Colorado river. In order to calculate the concentration of fine sediment (silt and clay sized) and coarse sediment (sands) separately, they used the amplitude of the backscattered intensity data from side-looking ADCPs as a proxy for sand and the acoustic attenuation as a proxy for silts and clays. Their results were in good agreement with physical samples and with concentrations measured in-situ with a laser-diffraction instrument. Since fine and coarse sediment have different mechanical behaviour (washload vs. bed material load) and play different roles in pollutant transfer and sedimentation, the ability to distinguish these two size classes using acoustic backscatter data is a significant advantage for the study of sediment transport processes.

The first objective of this paper is to build on the work of Topping et al. (2007), Wright et al. (2010) and Moore et al. (2012) by presenting further data which support the use of sediment attenuation as a proxy for fine sediment. Concentration estimates based on attenuation are less sensitive to changes in grain size than are estimates based on the backscattered intensity because attenuation depends roughly on $a$ for fine sediments, while backscatter depends on $a^{3}$. The attenuation-based method is therefore much more robust for silt and clay sized particles than is the backscattered intensity method.

The majority of published laboratory work on acoustic scattering by suspended sediments has focused on sand-sized particles (see the review papers by Thorne and Hanes, 2002; Thorne and Meral, 2008) and the formulation for viscous absorption is not presented in these papers since it is negligible for coarse sediment. Although many authors correctly account for the appropriate attenuation in their interpretation of backscatter data (e.g. Gartner, 2004; Ha et al., 2011; Hoitink and Hoekstra, 2005), there are cases where the formulations for sand have been used on measurements made in environments where fine particles are dominant, such as the work on the Paraná river by Guerrero et al. (2011). This can lead to misinterpretation of the data. Therefore, the second objective of this paper is to highlight the need to account for attenuation due to both viscous absorption and scattering by suspended sediment in the interpretation of acoustic backscatter data acquired in environments where fine sediments are present. This is important because acoustic backscatter systems are being increasingly used to measure sediment transport throughout river cross sections and 
at distances far from the bed, where fine sediments are typically more abundant than sand. The final and main objective of this paper is to present an original method for determining a representative grain size of the particles in suspension using attenuation data at multiple frequencies. Although the attenuation measurements presented in this paper were obtained using side-looking ADCPs, our multi-frequency sizing method can be applied to acoustic data from any backscatter profiler.

\section{THEORY}

For incoherent scattering from a homogeneous suspension of particles of radius $a$, the square of the root-mean-square backscattered voltage, $V_{\mathrm{rms}}$, that is recorded by a monostatic piston transducer can be written as (Hay, 1991; Thorne and Hanes, 2002)

$$
V_{\mathrm{rms}}^{2}=\frac{k_{s}^{2} k_{t}^{2}}{\Psi^{2} r^{2}} M e^{-4 r\left(\alpha_{w}+\alpha_{s}\right)}
$$

where

$$
k_{s}^{2}=\frac{\int_{0}^{\infty} a^{2} f_{\infty}^{2} n(a) d a}{\rho_{s} \int_{0}^{\infty} a^{3} n(a) d a},
$$

$f_{\infty}$ is the backscatter form function, which is proportional to the projected area of the particles, $\rho_{s}$ is the particle density and $n(a)$ is the probability density function, PDF, of the size distribution by number of particles. The symbol $k_{t}$ is the system constant, $r$ is the range from the transducer to the insonified volume, $\Psi$ is the near field correction factor (Downing et al., 1995), $M$ is the mass concentration of scatterers, $\alpha_{w}$ is the attenuation due to water and $\alpha_{s}$ is the attenuation due to suspended sediment. The expression for the attenuation due to water that was used in this work is (Fisher and Simmons, 1977):

$$
\alpha_{w}\left[\mathrm{~m}^{-1}\right]=\left(55.9-2.37 T+4.77 \times 10^{-2} T^{2}-3.48 \times 10^{-4} T^{3}\right) 10^{-15} f^{2}
$$

where $T$ is the water temperature in degrees Celsius and $f$ is the frequency in Hz. The pressure term was neglected in Equation 3, since the maximum measurement depth is $5 \mathrm{~m}$. As an example, $\alpha_{w}$ is $0.0035 \mathrm{~m}^{-1}$ at $10^{\circ} \mathrm{C}$ and $307.2 \mathrm{kHz}$, which is the nominal frequency of an RD Instruments $300 \mathrm{kHz} \mathrm{H}-\mathrm{ADCP}$.

The sediment attenuation can be due to the viscous drag between the fluid and the 
suspended particles or due to scattering of the sound in directions other than $180^{\circ}$; the former is referred to as viscous attenuation, $\alpha_{s}$, visc , and the latter is referred to as scattering attenuation, $\alpha_{s, \text { scat }}$ The total sediment attenuation, $\alpha_{s}$, can be expressed in terms of the ensemble averaged viscous and scattering attenuation coefficients, $\left\langle\zeta_{v}\right\rangle$ and $\left\langle\zeta_{s}\right\rangle$, as (e.g. Hay, 1983)

$$
\alpha_{s}=\alpha_{s, \text { visc }}+\alpha_{s, \text { scat }}=M\left\langle\zeta_{v}\right\rangle+M\left\langle\zeta_{s}\right\rangle
$$

assuming that both concentration and grain size are constant throughout the insonified water over which $\alpha_{s}$ is determined.

The ensemble averaged scattering attenuation coefficient can be written as (Thorne and Meral, 2008)

$$
\left\langle\zeta_{s}\right\rangle=\frac{3 \int_{0}^{\infty} a^{2} \chi n(a) d a}{4 \rho_{s} \int_{0}^{\infty} a^{3} n(a) d a}
$$

where

$$
\chi=\frac{0.29 x^{4}}{0.95+1.28 x^{2}+0.25 x^{4}}
$$

for quartz based sediments and $x=k a$. For monosized spherical particles, the viscous attenuation coefficient, $\zeta_{v}(a)$, is (Urick, 1948):

$$
\begin{aligned}
\zeta_{v}(a) & =\frac{k(g-1)^{2}}{2 \rho_{s}}\left[\frac{s}{s^{2}+(g+\delta)^{2}}\right], \\
s & =\frac{9}{4 b a}\left[1+\frac{1}{b a}\right], \\
g & =\frac{\rho_{s}}{\rho}, \quad \delta=\frac{1}{2}\left[1+\frac{9}{2 b a}\right], \quad b=\sqrt{\frac{\omega}{2 \nu}},
\end{aligned}
$$

where $\rho$ is the density of the fluid (water), $\nu$ is the kinematic viscosity of water and $\omega$ is the angular frequency. The value used for $\nu$ in this work was $1.3 \times 10^{-6} \mathrm{~m}^{2} / \mathrm{s}$. According to Urick (1948, p. 288), the ensemble averaged viscous attenuation from a suspension of particles with a given size distribution is obtained by dividing the size distribution curve into segments of equal range of concentration, and adding the absorption values calculated for 
each smaller range of particle size. This is equivalent to multiplying the total concentration, $M$, by the viscous attenuation coefficient integrated over the PDF of the size distribution by volume, $v(a)$, which is also equivalent to the following:

$$
\left\langle\alpha_{s, \text { visc }}\right\rangle=M \frac{\int_{0}^{\infty} \zeta_{v}(a) a^{3} n(a) d a}{\int_{0}^{\infty} a^{3} n(a) d a} .
$$

In our previously published work on sediment attenuation (Moore, 2012; Moore et al., 2012), it was assumed that the mass concentration of all size classes were identical, so that the ensemble averaged viscous sediment attenuation was expressed as $\left\langle\alpha_{s \text {, visc }}\right\rangle=$ $M \int_{0}^{\infty} \zeta_{v}(a) n(a) d a$. This is not equivalent to Equation 8 and the implications of this difference will be discussed later in this paper.

Although Equations 7 and 8 were derived for spherical particles, both Urick (1948) and Richards et al. (2003) found reasonable agreement between this model and attenuation from natural sediment particles. However, Richards et al. (2003) also compared their laboratory measurements of absorption at $50-150 \mathrm{kHz}$ in dilute suspensions of highly non-spherical and natural marine sediment particles to a model for viscous attenuation from a suspension of oblate spheroids. They found especially good agreement between the model and measurements with plate-like kaolin particles. In their model for natural marine sediment particles, Richards et al. (2003) assumed that two-thirds of the particles were oblate spheroids oriented parallel to the acoustic field and one-third were oblate spheroids oriented perpendicular to the field. This was done to account for the particles being oriented along their three independent spatial axes, one of which is in the broadside direction and two of which are in the edgewise direction. They used the formulations presented in Ahuja and Hendee (1978) to calculate the viscous absorption coefficient for these two cases and tested aspect ratios, $h$, of $1 / 10$ and $1 / 40$.

Figure 1 is a plot of the viscous and scattering attenuation coefficients calculated for mono-sized particles as a function of grain size for the operating frequencies of the H-ADCPs used in this study: $307.2,614.4$ and $1228.8 \mathrm{kHz}$. In this figure, the viscous attenuation has been calculated assuming spherical particles. The total sediment attenuation coefficient is superimposed on these curves. It can be seen that the viscous attenuation is greater than the scattering attenuation for all particles with radii less than $\sim 50 \mu \mathrm{m}$ for the $1200 \mathrm{kHz}$ instrument, $\sim 90 \mu \mathrm{m}$ for the $600 \mathrm{kHz}$ instrument and $\sim 160 \mu \mathrm{m}$ for the $300 \mathrm{kHz}$ instrument. It 
can also be seen that the viscous absorption is approximately a linear function of frequency.

In Section III, it will be seen that the PDFs of the size distribution by volume of particles, $v(a)$, that were measured in water samples were reasonably well represented by log-normal distributions of the form

$$
v(a)=\frac{1}{a \sigma \sqrt{2 \pi}} \exp \left[-\frac{\left(\ln a-\ln a_{g}\right)^{2}}{2 \sigma^{2}}\right]
$$

where $a_{g}$ is the geometric mean of $a$ and $\sigma$ is the scale parameter, which was equal to one for our samples (Moore, 2012). For a lognormal distribution of a variable, the geometric mean is equal to the median value, thus $a_{g}=a_{50 \text {, vol }}$ in the above equation. The ensemble averaged attenuation coefficients calculated for particles with log-normal distributions by volume are shown in Figure 2 as a function of $a_{50}$, vol. At each value of $a_{50, \text { vol }}$, the attenuation coefficients have been averaged over the appropriate distributions following Equations 5 and 8. In order to convert from volume size distributions to number size distributions we do the following. If $\operatorname{volFrac}_{i}$ is the fraction of particles in size class $i$ relative to the total volume of particles, then the fraction of particles by number, numFrac $i$, is

$$
\operatorname{numFrac}_{i}=\frac{\operatorname{volFrac}_{i} / \operatorname{vol}_{i}}{\sum_{i}\left(\operatorname{volFrac}_{i} / \operatorname{vol}_{i}\right)}
$$

where $\operatorname{vol}_{i}$ is the volume of a sphere of radius $a_{i}, n\left(a_{i}\right)=\operatorname{numFrac}_{i} / \Delta a_{i}$ and $v\left(a_{i}\right)=$ $\operatorname{volFrac}_{i} / \Delta a_{i}$ where $\Delta a_{i}$ is the width of size class $i$. 


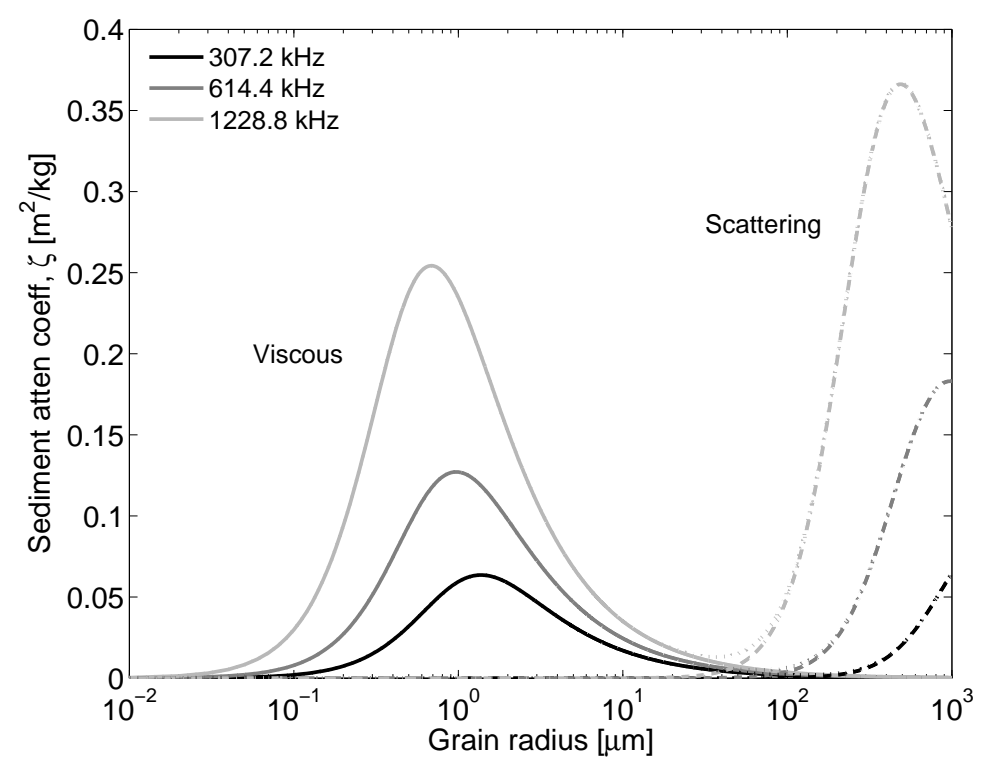

Figure 1 The viscous (-), scattering (-.-) and total attenuation coefficients (...) for a suspension of mono-sized particles as a function of particle radius for the operating frequencies of the H-ADCPs. The viscous attenuation is calculated assuming spherical particles.

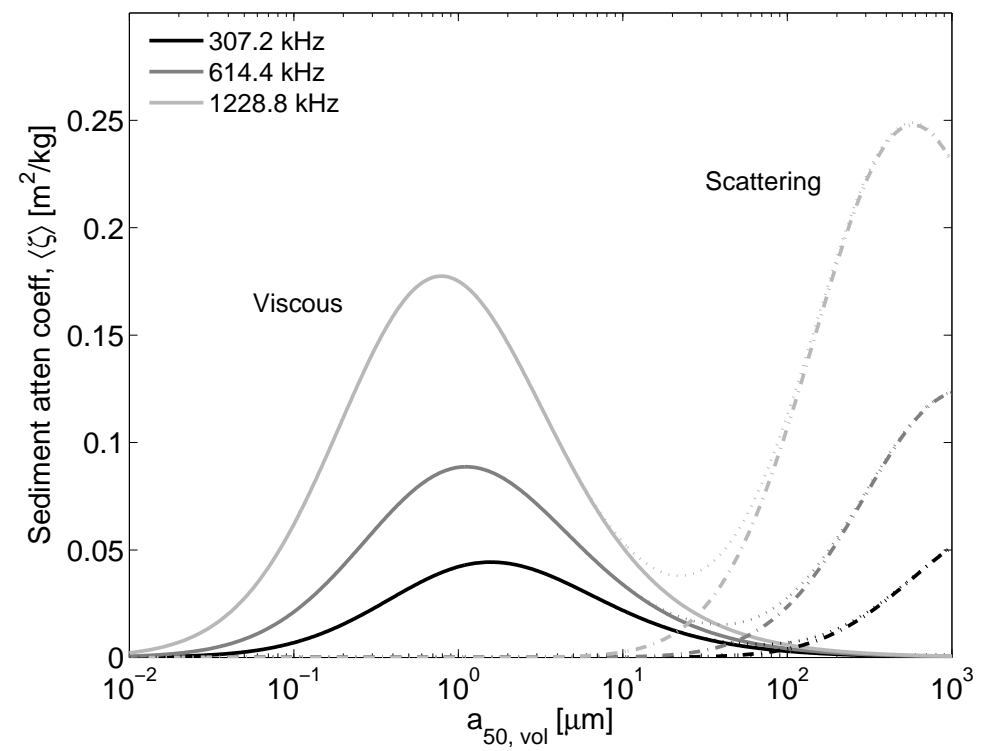

Figure 2 The viscous (-), scattering (-.-) and total attenuation coefficients (...) for a suspension of particles having log-normal distributions by volume with $\sigma=1$, as a function of median radius by volume, $a_{50 \mathrm{vol}}$, for the operating frequencies of the H-ADCPs. The viscous attenuation is calculated assuming spherical particles.

Noting the different y scales of Figures 1 and 2, it can be seen that averaging over the size distributions results in a flattening and widening of the viscous absorption and scattering peaks compared to the single size case. Figure 3 is a plot of the viscous attenuation coefficient 
calculated for a suspension of monosized oblate spheroids with aspect ratios of $h=1 / 10$ and 1/40, following the theory outlined in Richards et al. (2003). The values are plotted as a function of the radius of an equal volume sphere. It can be seen that the maximum viscous attenuation from a suspension of oblate spheroids at a given frequency is less than it is for a suspension of spherical particles with the same volume. Figures 1 to 3 show that if the attenuation is converted to concentration using a theoretical sediment attenuation coefficient, then the assumptions made about particle size distribution and shape in the calculation of the theoretical coefficient will impact the estimation of concentration.

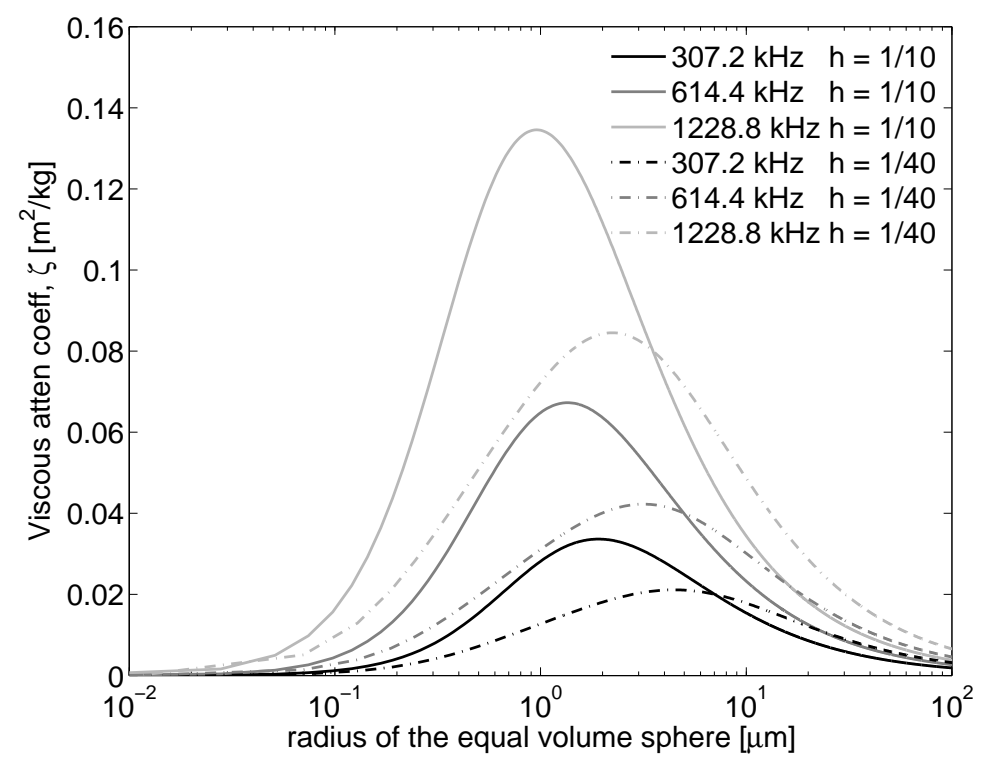

Figure 3 The viscous absorption coefficients for a suspension of mono-sized oblate spheroids with aspect ratios of $h=1 / 10$ and $1 / 40$ as a function of the radius of an equal volume sphere for the operating frequencies of the H-ADCPs.

\section{STUDY SITE}

All measurements were made at the Romans-sur-Isère study site on the Isère river in SouthEast France. The catchment basin of the Isère river is very mountainous and there are a number of hydroelectric structures both upstream and downstream of the study site. It is $6 \mathrm{~km}$ upstream of the La Vanelle dam and $2 \mathrm{~km}$ downstream of the Pizançon dam, both of which are operated by Electricité de France. The section at which measurements were made is roughly $90 \mathrm{~m}$ wide and the maximum depth is about $4 \mathrm{~m}$. The average bathymetry measured during gauging with a $600 \mathrm{kHz}$ ADCP on January 9, 2009 is shown in Figure 4. 
Measurements made during an extensive sampling campaign in March 2009 showed that both concentration and grain size were homogeneous throughout the measurement cross section (Moore et al., 2012), validating the assumption used to obtain Equation 4.

During most of the year, the cross-sectional averaged flow speed typically ranges from $0.25 \mathrm{~m} / \mathrm{s}$ to $1.5 \mathrm{~m} / \mathrm{s}$ and suspended sediment concentrations range from $10 \mathrm{mg} / \mathrm{L}$ to $30 \mathrm{mg} / \mathrm{L}$. Floods tend to occur during the spring snowmelt and during rain storms. The mean discharge during floods can exceed $1000 \mathrm{~m}^{3} / \mathrm{s}$ and concentrations can range from $1 \mathrm{~g} / \mathrm{L}$ to $10 \mathrm{~g} / \mathrm{L}$. There is high washload content during floods due to the mountainous and erodible catchment. Since dam gates can be opened wider than usual during floods to allow the sediment from further upstream to continue downstream, there can be resuspension of silt and sand trapped behind dams and on margins during rising flow periods. There may also be resuspension of particles during certain dam operations.

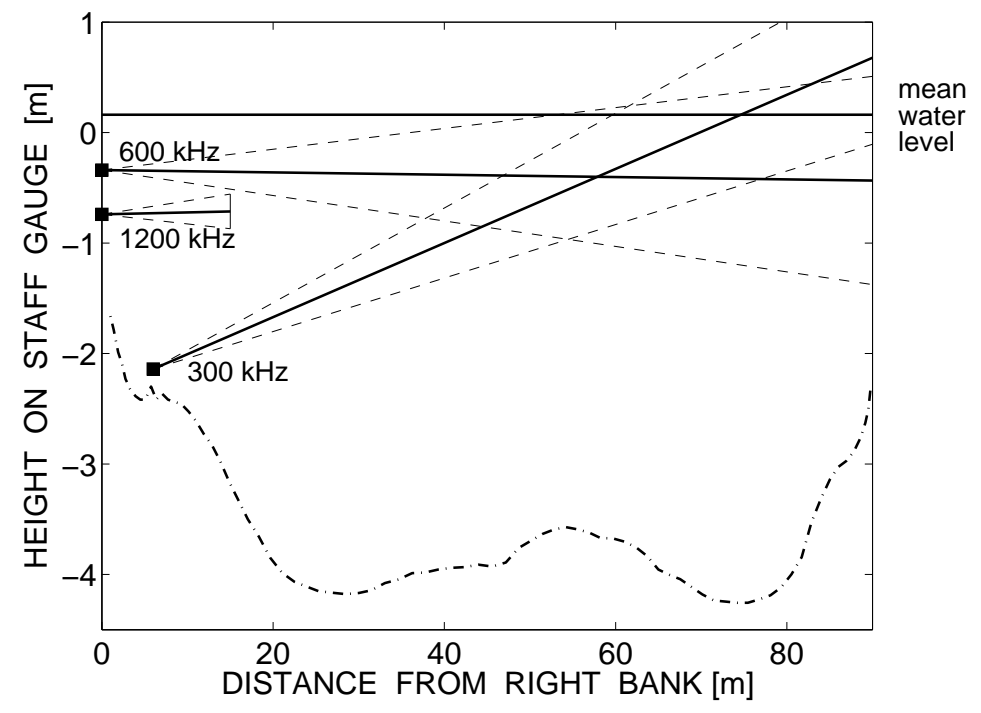

Figure 4 Upstream view of the study site. The solid horizontal line indicates the annual mean water level and the dashed-dotted line is the bottom. Squares represent the H-ADCPs. The solid lines represent the projections of the axes of the central transducers of 300 and $600 \mathrm{kHz}$ instruments and of either of the $1200 \mathrm{kHz}$ transducers; the dashed lines represent their beam widths (the angular width of the main lobe at half intensity).

Measurements were made with three Teledyne RD Instruments H-ADCPs (300, 600 and $1200 \mathrm{kHz}$ ) which were operated by the Compagnie Nationale du Rhône. The central frequencies of the three instruments were $307.2 \mathrm{kHz}, 614.4 \mathrm{kHz}$ and $1228.8 \mathrm{kHz}$, respectively. The $300 \mathrm{kHz}$ instrument was a Workhorse model, the $600 \mathrm{kHz}$ instrument was a Workhorse prototype and the $1200 \mathrm{kHz}$ instrument was a Channel Master model. The instruments were 
installed as shown in Figure 4. Their depth, pitch and roll are listed in Table I along with the instrument specifications. An image of the right bank of the study site is provided in Figure 5 .

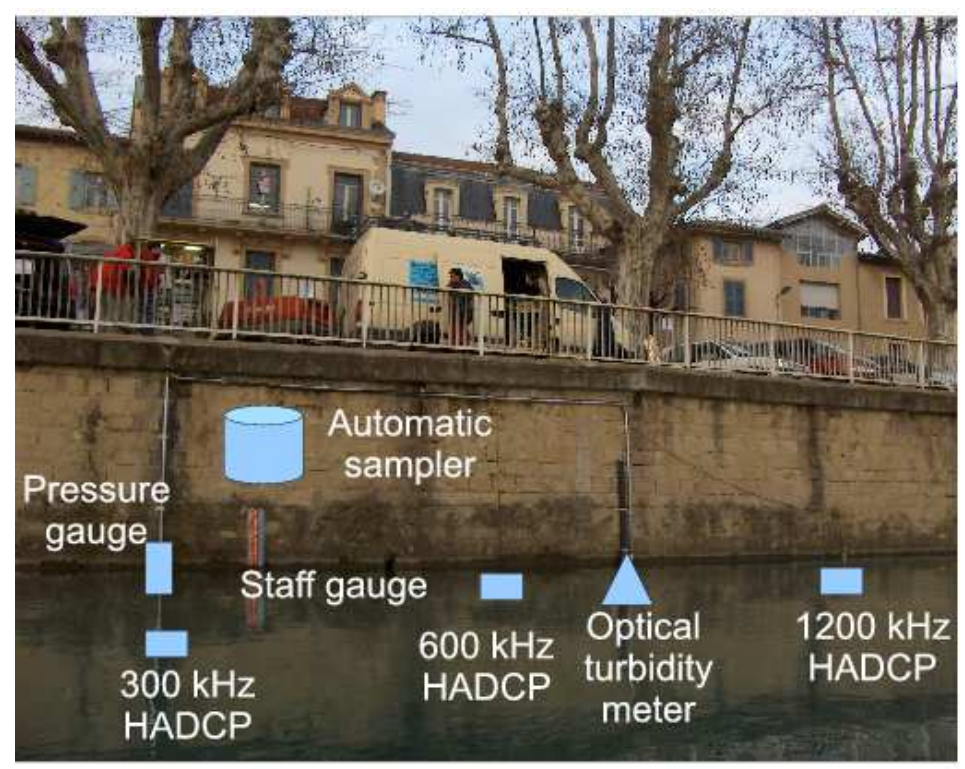

Figure 5 The Romans-sur-Isère study site (Color online). All instruments are installed along the wall of the right bank except the $300 \mathrm{kHz} \mathrm{H}-\mathrm{ADCP}$ which is attached to a $6-\mathrm{m}$ long arm. To give an idea of scale, the thick vertical bars of the railing are separated by $2 \mathrm{~m}$.

In order to avoid potential interference amongst the H-ADCPs, they were programmed to operate in turn. Each instrument transmitted and internally averaged the velocity and intensity data from 15 consecutive pings every 75 seconds. The transmit pulse length and size of the range gates that were used corresponded to the manufacturer's recommendations for this site. The cell size was $2 \mathrm{~m}$ for the $300 \mathrm{kHz}$ H-ADCP, $1 \mathrm{~m}$ for the $600 \mathrm{kHz} \mathrm{H}-\mathrm{ADCP}$ and $0.5 \mathrm{~m}$ for the $1200 \mathrm{kHz}$ instrument. The blanking distances were $1.75 \mathrm{~m}, 1.00 \mathrm{~m}$, and $0.50 \mathrm{~m}$, respectively. The instruments were operated in narrow bandwidth mode, meaning that a bandwidth filter of $6.25 \%$ of the central frequency was applied to the signal on reception (Teledyne RD Instruments, 2008, p. 162).

A Hach Lange SOLITAX sc optical turbidity meter was used to monitor suspended sediment concentration. It was installed at a depth of $0.5 \mathrm{~m}$ on the right bank of the river as shown in Figure 5. An ISCO 6712 peristaltic pump automatic sampler was used to sample at regular intervals during floods. The water intake of the sampler was at the same depth as the turbidity meter $(0.5 \mathrm{~m})$ and at the along-stream position of the $300 \mathrm{kHz} \mathrm{H}-\mathrm{ADCP}$. 
A linear relationship between concentration and turbidity was established with over 100 samples of surface water collected throughout the year, as shown in Figure 4 of Moore et al. (2012). The relationship was of the form $Y=0.96 X$, where $Y$ is the concentration in $\mathrm{mg} / \mathrm{L}$ and $X$ is the turbidity in $\mathrm{mg} / \mathrm{L}$ Total Suspended Solids (TSS). This relationship appeared to be independent of the various events, the time of year of sampling and the differences in the size distributions of the primary particles that were observed at this site. However, concentrations predicted with this relationship will likely be over-estimated when the actual concentration exceeds $200 \mathrm{mg} / \mathrm{L}$. This can be seen in Figure 10b of Moore et al. (2012) where concentration estimates from the turbidity meter are compared to water samples collected throughout a flood. The relative root mean square error between the samples and the estimates from the linear relationship for all samples for which the turbidity exceeded $50 \mathrm{mg} / \mathrm{L}$ TSS (i.e. all the data presented in this paper) was $32 \%$ due to this discrepancy at high concentrations.

Grain size analysis was performed in the laboratory on a selection of samples using a Malvern Mastersizer laser particle size analyzer. The choice of sizing method was motivated by instrument availability and by the fact that laser sizing is one of the few techniques capable of measuring micron-sized particles. Because several weeks typically elapsed between sampling and grain size analysis, ultrasonic waves were applied to the samples prior to analysis in order to break up flocs that may have formed during or after sampling. The size distributions that are measured are therefore representative of the primary particles in suspension. Using either the Mie or Fraunhofer theories of optical scattering, the instrument interprets the diffraction pattern as coming from a suspension of spheres with a particular size distribution (Wedd, 2003). Results are output as size distributions by volume and represent a measure of the effective spherical diameter of the particles for optical scattering. The drawback to this sizing method is that concentrations of $\sim 50 \mathrm{mg} / \mathrm{L}$ or higher are required for accurate measurements, thus samples collected outside of floods and dam-flushing events are not sufficiently concentrated for accurate measurements.

The grain size distributions measured in four surface water samples collected during various floods are shown in Figure 6 as PDFs of the size distributions by volume. These samples, which were all analysed in Fraunhofer mode, cover a range of concentration values from $60 \mathrm{mg} / \mathrm{L}$ to $5 \mathrm{~g} / \mathrm{L}$. The sample from May 11, 2010 was collected during the middle of two days of relatively high concentrations and flow speeds $(100 \mathrm{mg} / \mathrm{L}, 1.5 \mathrm{~m} / \mathrm{s})$. The sample 
from June 1 was collected near the peak of a large spring flood $(5 \mathrm{~g} / \mathrm{L}, 2.5 \mathrm{~m} / \mathrm{s})$, while the sample from June 3 was collected on the falling limb of this flood $(200 \mathrm{mg} / \mathrm{L}, 1.5 \mathrm{~m} / \mathrm{s})$. The sample collected in December was taken on the descent of a small winter flood (62 mg/L, velocity unmeasured). No organic particles were seen by the naked eye in these samples and thus the organic content was assumed to be small, but it was not assessed quantitatively and the samples were not treated prior to analysis. The concentration measured by filtration and the laser obscuration of each sample are listed in Table II as are the median diameters, $d_{50}$, of the distributions. These grain size distributions should be representative of the various distributions that can be observed at the study site during floods. The ensemble averaged viscous attenuation coefficients calculated for the four measured size distributions are presented in Table II.

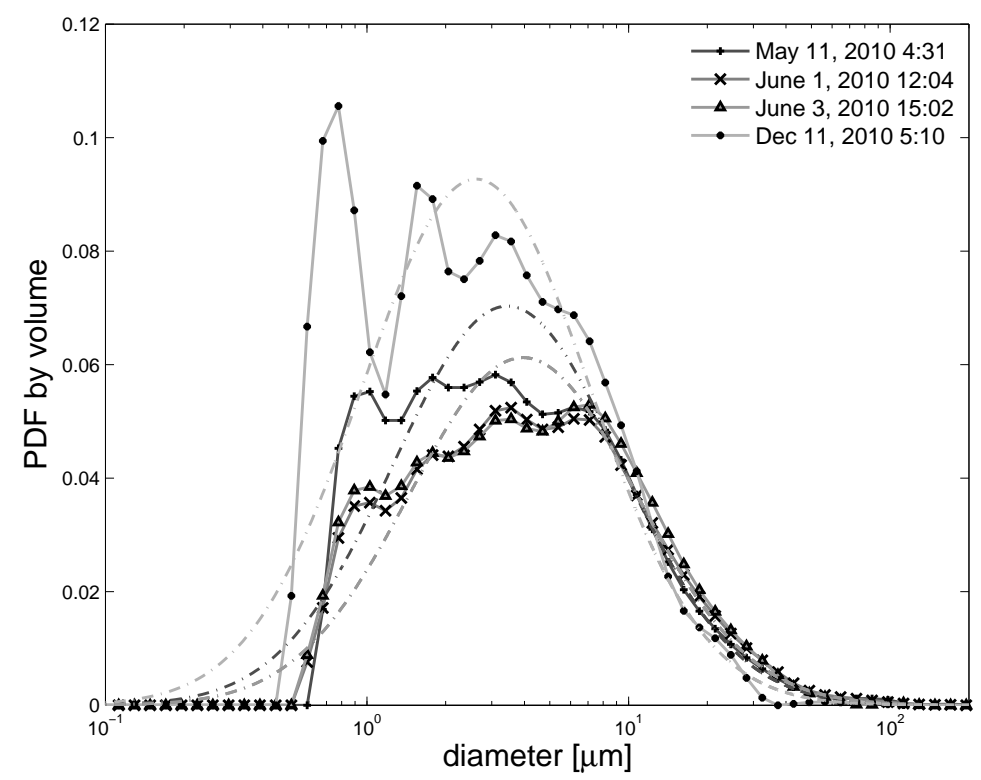

Figure 6 Probability density functions (PDFs) of the grain size distributions by volume of particles measured in water samples using a laser sizer in Fraunhofer mode: +, 2010-05-11 4:31; x, 201006-01 12:04; $\triangle$, 2010-06-03 15:02; *, 2010-12-11 5:10. Lognormal distributions by volume (-.-) calculated using the measured median diameters as the location parameter and $\sigma=1$ as the scale parameter. These curves are not fitted to the data.

Theoretical lognormal distributions calculated using the measured median diameter,

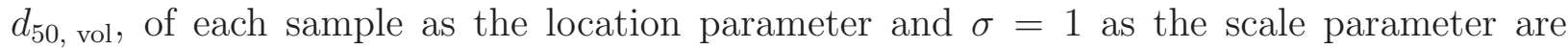
overlayed on the data in Figure 6. It can be seen that there is relatively good agreement between the form of the measured probability density functions and the lognormal distributions, except at diameters less than a few microns. 


\section{METHODS}

\section{A. Determination of concentration}

In order to calculate the sediment attenuation from the H-ADCP intensity data we use the data from one beam of each instrument. For the 300 and $600 \mathrm{kHz}$ instruments the acrossstream beam is typically used and for the $1200 \mathrm{kHz}$ (2-beam) instrument the downstream beam is used. The data are averaged over $15 \mathrm{~min}$ in order to reduce noise and file size. The sediment attenuation, $\alpha_{s}$, is calculated from the time-averaged intensity profiles following the procedure outlined in Wright et al. (2010) and Moore (2012). In short, the backscattered intensity in counts is first converted to decibels. It is then corrected for spherical spreading and attenuation by water by adding $20 \log _{10} r$ and $2 \alpha_{w}$ r, respectively, where $r$ is the distance of the measurement cell from the transducer and $\alpha_{w}$ is calculated using Equation 3. This yields the fluid-corrected backscatter. If the concentration and grain size are constant across the measured profile and if there is insufficient sediment to cause attenuation, then the fluid corrected backscattered intensity profile should be a horizontal line. If, however, there is detectable sediment attenuation, then the fluid-corrected intensity will decrease linearly with range and the slope of this line will be equal to $-2 \alpha_{s}$ in units of $\mathrm{dB} / \mathrm{m}$. This is converted to linear units by dividing by $8.686 \mathrm{~dB}$.

The calculation of sediment attenuation using the method described above relies on the assumption that grain size and concentration are homogeneous across all cells used to calculate $\alpha_{s}$, in this case the entire profile. All acoustic data and water samples collected at this study site confirm that this is a valid assumption, which is not surprising considering all measurement cells are about the same distance from the bottom, and the river is well mixed at this location. Our calculation of the sediment attenuation also relies on the assumption that the acoustic attenuation due to air bubbles is negligible. While work by Richards and Leighton (2001) suggests that the attenuation by a bubble population measured in calm coastal waters may be as high as $0.5 \mathrm{~dB} / \mathrm{m}$ at $300 \mathrm{kHz}$ and $0.3 \mathrm{~dB} / \mathrm{m}$ at $1 \mathrm{MHz}$, the data collected at our study site show no obvious signs of attenuation due to bubbles. In the 12-months of data that were analyzed, the attenuation that was observed during low concentration conditions always corresponded to the theoretical attenuation for pure water and the onset of detectable attenuation always coincided with increased concentrations of 
suspended sediment. Thus it seems justifiable to ignore the effect of microbubbles on the attenuation for the measurements presented in this paper.

Once the sediment attenuation has been determined from the intensity profile, it can be converted to concentration, $M$, using either an empirical or a theoretical method. Water samples collected along or near the intensity profiles are required for both methods. The empirical method consists in fitting a linear relationship between simultaneous and co-located measurements of $\alpha_{s}$ and $M$. Although the concentration data should ideally come from direct sampling, measurements made with a calibrated optical turbidity meter can also be used, provided its calibration relationship is relatively insensitive to the site-specific changes in grain size. The experimental value of the ensemble averaged attenuation coefficient, $\langle\zeta\rangle_{\exp }$, is defined to be:

$$
\langle\zeta\rangle_{\exp }=\frac{\alpha_{s}}{M}
$$

This value can then be used to convert further sediment attenuation data to concentration as:

$$
M=\frac{\alpha_{s}}{\langle\zeta\rangle_{\exp }}
$$

If the size distribution of the suspended sediment is unchanged from one acoustic measurement to the next, then there should be a unique linear relationship between $\alpha_{s}$ and $M$ with a y-intercept of zero (recall Equation 4). If a clear linear relationship cannot be established between $\alpha_{s}$ and $M$, then it can be concluded that the grain size distribution was not constant. Thus, an interesting way to examine the potential evolution of grain size of the suspended load during floods or dam flushing events is to progressively plot sediment attenuation versus concentration. If successive values of $\alpha_{s}$ do not fall on the same line, then it can be deduced that the size of the suspended sediment changed with time.

The second method to convert attenuation to concentration consists in assuming a particular grain size distribution and calculating the theoretical sediment attenuation coefficients. The concentration is therefore calculated as

$$
M=\frac{\alpha_{s}}{\left\langle\zeta_{v}\right\rangle+\left\langle\zeta_{s}\right\rangle}
$$


Tied up in this method are assumptions about the shape and mineralogy of the particles, as well as the assumption that the size distributions measured in the laboratory are the same as those in the field. As a consequence, if there are only measurements at one frequency, it is preferable to use the empirical method for the determination of concentration since the only assumption made is that the concentration at the location of the water sample corresponds to the concentration across the profile.

\section{B. Measuring grain size with multi-frequency attenuation data}

Since multiple instruments measuring the backscatter at roughly the same time in roughly the same volume of water should detect scattering from the same particles, multi-frequency backscatter data can be used to determine both concentration and grain size. For suspensions of particles that have size distributions with a single dominant mode, multi-frequency acoustic backscatter data can be used to determine a representative size of the particles in suspension, this is often the mean or median diameter. This was first done by Hay and Sheng (1992) and their method was later adapted by Crawford and Hay (1993), Thorne and Hardcastle (1997), Thosteson and Hanes (1998) and Moate and Thorne (2009), among others.

Crawford and Hay (1993) took the mean size of sediments with a log-normal distribution to be the particle radius that minimized the difference between the ratios of the detected voltage to the theoretical ensemble scattering function at two frequencies. Rather intuitively, multi-frequency attenuation data can also be used to obtain an estimate of grain size. Following the approach of Crawford and Hay (1993), our method consists in determining a representative grain size of the suspended sediment by minimizing the difference between concentration estimates from attenuation data at two frequencies. If $\left\langle\zeta_{i}\right\rangle=\left\langle\zeta_{v}\right\rangle+\left\langle\zeta_{s}\right\rangle$ is the total theoretical ensemble averaged sediment attenuation coefficient at frequency $i$ for a given size distribution of particles, then $\alpha_{s i} /\left\langle\zeta_{i}\right\rangle$ is the concentration of particles with that size distribution required to produce the observed attenuation, $\alpha_{s i}$. Thus, for a given theoretical grain size distribution,

$$
\epsilon_{i, j}=\frac{\alpha_{s i}}{\left\langle\zeta_{i}\right\rangle}-\frac{\alpha_{s j}}{\left\langle\zeta_{j}\right\rangle}
$$

is the difference between concentration estimates at frequencies $i$ and $j$. Assuming mono- 
sized spheres, the acoustic estimate of $a$ is taken to be the radius that minimizes the sum of $\left|\epsilon_{i, j}\right|$ for the three frequency combinations. Three frequencies are needed because the attenuation is not monotonic (see Figure 1), meaning that there may be multiple values of $a$ that minimizes $\epsilon_{i, j}$ for a given frequency pair.

Since the grain size distributions by volume measured by laser grain sizer in water samples collected at our study site were reasonably well represented by log-normal distributions with $\sigma=1$, the theoretical viscous attenuation coefficients from Figure 2 can also be used in Equation 14. In this case, the size estimate obtained by minimizing $\sum\left|\epsilon_{i, j}\right|$ is a measure of $a_{50 \text {, vol }}$ Recalling the similarity between Figures 1 and 2 , this value should be close to the value of $a$ obtained when assuming monosized particles. If, however, the width or type of the size distribution were different, this might not be the case (see Moate and Thorne (2009) for a discussion of the impact of the width and type of size distribution on the ensemble scattering parameters). Alternatively, the theoretical attenuation coefficients can be calculated for a suspension of oblate spheroidal particles assuming a particular aspect ratio.

Figure 7 depicts the values of $\epsilon_{i, j}$ and $\sum\left|\epsilon_{i, j}\right|$ obtained assuming monosized oblate spheroids with $h=1 / 10$ as a function of the radius of an equal volume sphere for 15 minutes of data collected between 12:00 and 12:15 near the peak of a flood on June 1, 2010. These data were selected for the demonstration because a sample was collected at 12:04 and analyzed for grain size (see Figure 6 and Table II). The measured median radius was $5.8 \mu \mathrm{m}$. The concentration calculated from the turbidity data at this time was $7.92 \mathrm{~g} / \mathrm{L}$ while the concentration measured by filtration was $6.05 \mathrm{~g} / \mathrm{L}$. As can be seen from Figure 7, the radius of an equal volume sphere that minimizes $\sum\left|\epsilon_{i, j}\right|$ for the spheroid model is $1.70 \mu \mathrm{m}$. The radius that is predicted assuming mono-sized spheres is $1.13 \mu \mathrm{m}$ and the value of $a_{50 \text {, vol }}$ predicted assuming spheres with a lognormal size distribution is $1.58 \mu \mathrm{m}$. The negligible difference between these values suggests that the assumptions about the shape of the particles and the form of $v(a)$ did not affect the estimate of size substantially in this case. Considering the uncertainty in the laser grain sizer measurements of the finest particles and the fact that optical and acoustical sizing techniques measure different parameters, the agreement between the optical and acoustical estimates of grain size is quite good.

As far as the authors are aware, this technique for determining grain size from multifrequency attenuation data is new. Although Topping et al. (2007) presented multi-frequency 


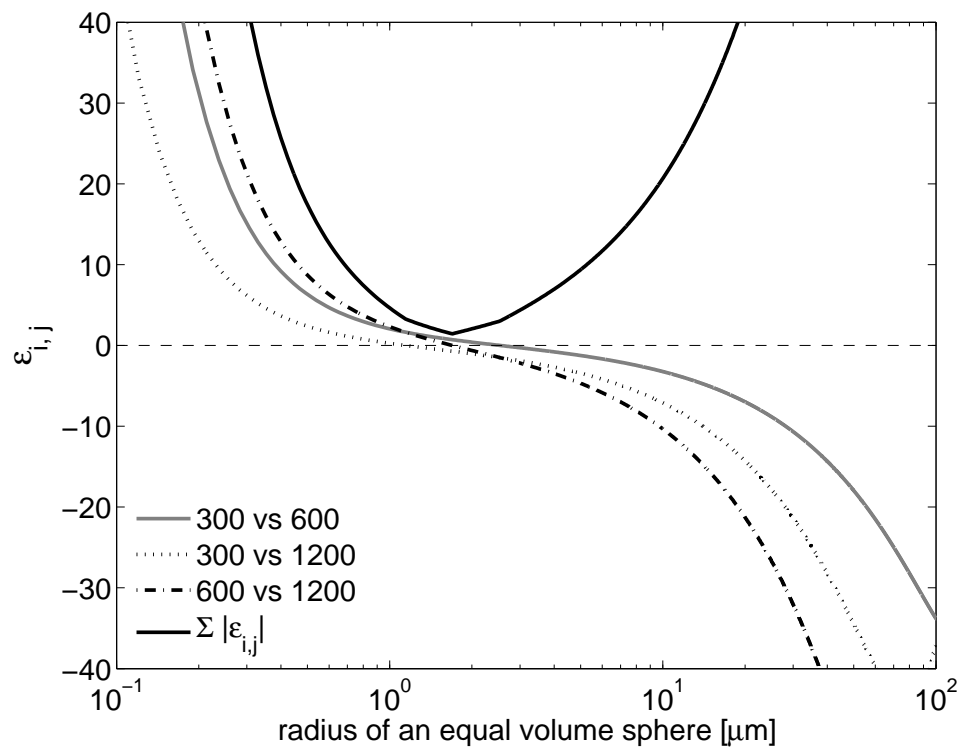

Figure 7 Values of $\epsilon_{i, j}$ and $\Sigma\left|\epsilon_{i, j}\right|$ calculated using attenuation data collected between 12:00 and 12:15 on June 1, 2010 assuming monosized oblate spheroids with aspect ratios of $1 / 10$, where $\epsilon_{i, j}$ is the difference between the concentration estimates at frequencies $i$ and $j$.

attenuation measurements, they analyzed the data at each frequency separately. For each acoustic instrument they used multiple months of concentration and attenuation data to determine the grain size that best corresponded to Urick's theory for monosized particles (Equation 7). The main advantage of our multi-frequency sizing method is that it can be used to monitor the temporal evolution of the size of suspended sediment during high concentration events such as floods, as will be shown in Section V. This method can also be used to monitor changes in grain size from event to event.

\section{RESULTS}

\section{A. Concentration measurements}

Measurements of concentration obtained from multi-frequency attenuation data at the Romans-sur-Isère study site were presented in Moore et al. (2012). Event-specific relationships were established between concentration values from the calibrated optical turbidity meter and the attenuation at three frequencies during a natural flood that occurred between May 31 and June 3, 2010 (Event A) and during a high-concentration event which resulted from dam operations upstream on June 30, 2010 (Event B). There were clear linear relation- 
ships between concentration and sediment attenuation at all frequencies throughout each event. As discussed in Moore et al. (2012), this indicates that the size distribution of the suspended sediment remained constant throughout each event. Although no water samples were collected during Event $\mathbf{B}$, grain size analysis performed on multiple samples collected during the falling limb of Event A (see Figure 6 for one example) confirmed that the PDFs of the size distributions changed negligibly throughout the event (Moore, 2012).

The experimental values of the ensemble averaged attenuation coefficient, $\langle\zeta\rangle_{\text {exp }}$, were obtained from the slopes of the least-squares fit linear relationships between $\alpha_{s}$ and $M$ for these two events. The values of $\langle\zeta\rangle_{\exp }$ obtained at all frequencies for Event $\mathbf{B}$ are approximately two-thirds of the values obtained during Event A (0.020, 0.040, 0.077 vs. $0.032,0.059,0.115) \mathrm{m}^{2} / \mathrm{kg}$ at 300,600 and $1200 \mathrm{kHz}$, respectively. This difference between events implies that the nature of the suspended sediment (size, shape or mineralogy) differed for the two events. The values presented in Table IV of Moore et al. (2012) are lower than the values presented here by $0.003 \mathrm{~m}^{2} / \mathrm{kg}$ at $300 \mathrm{kHz}$ and by $0.006 \mathrm{~m}^{2} / \mathrm{kg}$ at $600 \mathrm{kHz}$. At the time Moore et al. (2012) was published, the sediment attenuation was calculated between neighboring measurement cells; this is a less robust method than using the trend of the entire profile, as is currently done.

Theoretical values of the sediment attenuation coefficients can be calculated for spherical particles having the grain size distributions that were measured in the water samples collected during Event A. This is done using the equations presented in Section II. Theoretical values for these water samples were also presented in Table 3 of Moore et al. (2012) however, as mentioned in Section II, the sediment attenuation coefficients were incorrectly averaged over the PDF by number and not by volume. With the present calculation, there is excellent agreement between the theoretical and experimental values at $300 \mathrm{kHz}$, but the agreement worsens with increasing frequency. The empirical value at $300 \mathrm{kHz}$ was $0.032 \mathrm{~m}^{2} / \mathrm{kg}$ while the average theoretical value for this event was $0.030 \mathrm{~m}^{2} / \mathrm{kg}$. The empirical value at $600 \mathrm{kHz}$ is $20 \%$ larger than the average theoretical value $\left(0.059 \mathrm{~m}^{2} / \mathrm{kg}\right.$ versus $\left.0.050 \mathrm{~m}^{2} / \mathrm{kg}\right)$, while the empirical value at $1200 \mathrm{kHz}$ is $40 \%$ larger than the average theoretical value $\left(0.115 \mathrm{~m}^{2} / \mathrm{kg}\right.$ versus $0.080 \mathrm{~m}^{2} / \mathrm{kg}$ ). The values presented in Moore et al. (2012) were $0.034 \mathrm{~m}^{2} / \mathrm{kg}$ at $300 \mathrm{kHz}, 0.090 \mathrm{~m}^{2} / \mathrm{kg}$ at $600 \mathrm{kHz}$ and $0.214 \mathrm{~m}^{2} / \mathrm{kg}$ at $1200 \mathrm{kHz}$, thus it can be seen that the theory agrees better with the observations when the averaging is performed correctly. The finding that the agreement between the spherical model and the experimental data 
worsens with increasing frequency is consistent with the laboratory results of Richards et al. (2003), where it was shown that there was increasing discrepancy between the spherical and aspherical models and between the spherical model and the data as the frequency increased beyond $100 \mathrm{kHz}$. However, in their case the spherical model overestimated the attenuation whereas it under-estimates the attenuation here. This difference may be related to the fact that the grain size distributions used in their calculations were measured by sedimentation and not by laser diffraction as was done here.

Figure 8 is a plot of the concentration calculated from the attenuation data from Event B using the values of $\langle\zeta\rangle_{\exp }$ obtained during Event A. Using the concentration from the optical turbidity meter as the reference, it can be seen that the timing and overall form of the sediment transport event are well described by all H-ADCPs. However, as expected, the concentration estimates are about two-thirds the values measured by the turbidity meter.

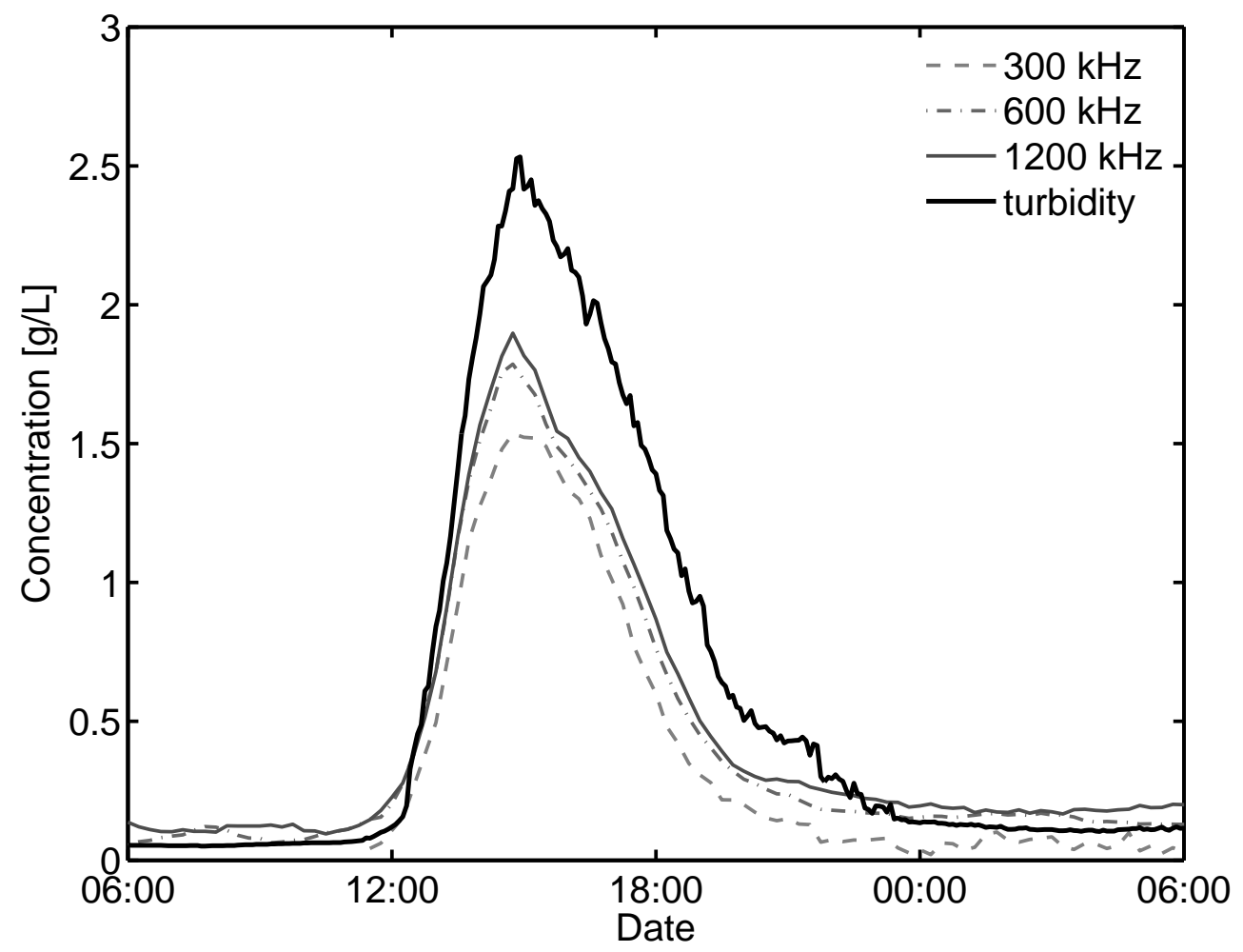

Figure 8 Concentrations measured by the H-ADCPs during Event $\mathbf{B}$ using the empirical attenuation coefficients calculated from Event A, compared to measurements from the optical turbidity meter.

Further attenuation data were collected during subsequent floods in June 2010. Data collected during a flood that occurred between June 16 and June 20, 2010 (Event C) make 
for an interesting case study. The concentration estimates from the $1200 \mathrm{kHz}$ data are shown in Figure 9, where the empirical attenuation coefficient from Event $\mathbf{A}$ has been used to convert the attenuation to concentration. For the most part, there is less discrepancy between the optical and acoustical estimates of concentration for this event than there was for Event B. However, unlike Event B, the features of the two time series are not identical, as can be seen from the sharp peak in attenuation on the rise of the flood that does not correspond with a peak in turbidity. This feature, which lasted about 1.5 hours, suggests that there was a temporary change in the grain size of the suspended sediment. Unfortunately no water samples were collected throughout this event in order to test this hypothesis.

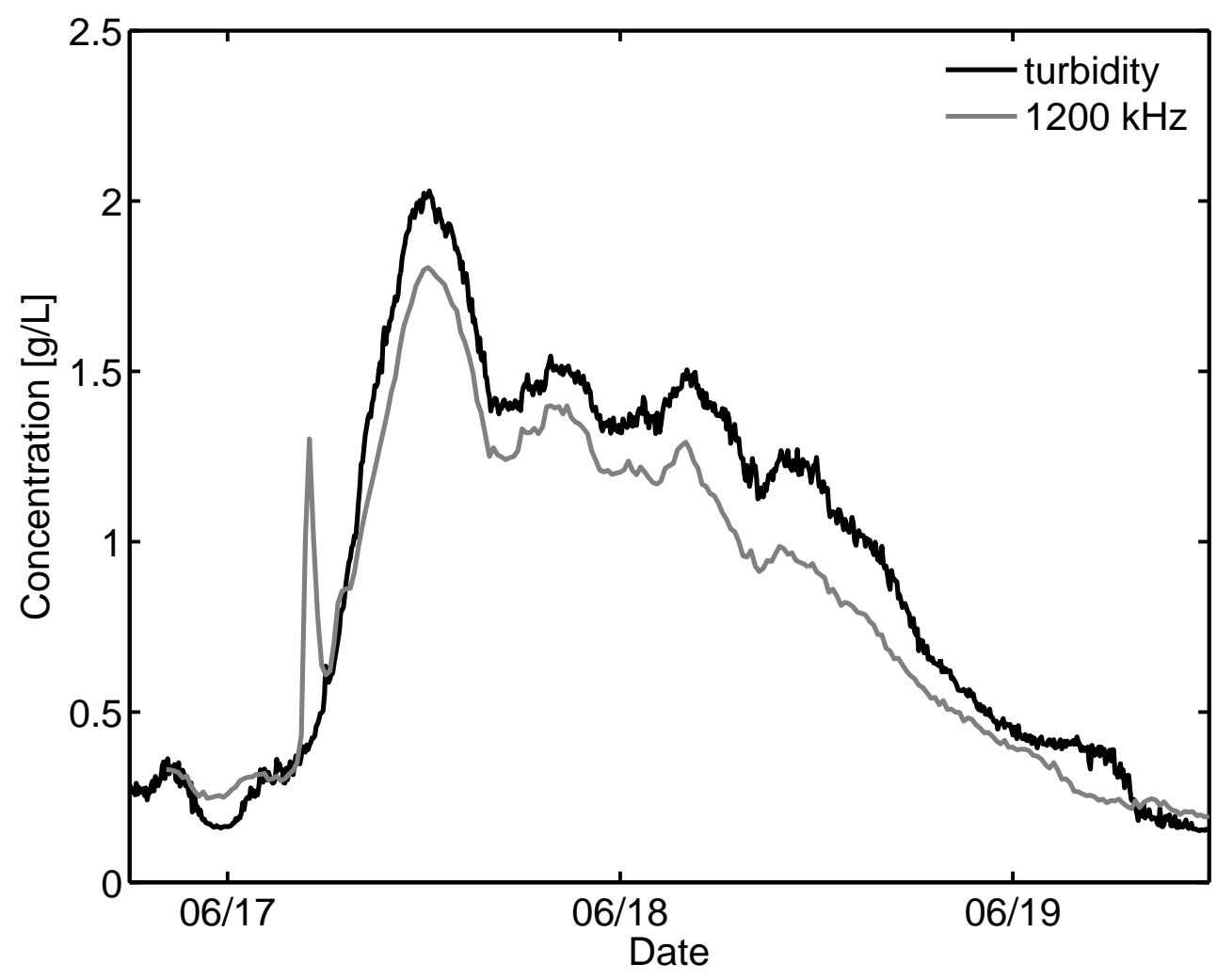

Figure 9 Event C: Concentration values measured with the turbidity meter compared to estimates from the $1200 \mathrm{kHz}$ attenuation using the empirical attenuation coefficient from Event $\mathbf{A}$ in the conversion.

Figure 10 is a plot of the sediment attenuation measured at the three frequencies as a function of concentration (from turbidity) for this event. The progression of $\alpha_{s}$ versus concentration with time is clockwise in the beginning, it then does a figure eight. The peak in the $1200 \mathrm{kHz}$ attenuation which occurred at a concentration of $0.4 \mathrm{~g} / \mathrm{L}$ on the rising limb of the flood is also seen in the $600 \mathrm{kHz}$ data, though to a lesser extent. There is also a slight 
peak in the $300 \mathrm{kHz}$ attenuation. This suggests that the $1200 \mathrm{kHz}$ instrument was detecting attenuation from particles to which the lower frequency instruments were less sensitive. This would be the case if sand from the bottom was eroded into suspension at the start of the flood (see Figure 1). This is a distinct possibility since dam gates can be opened wider than usual at the start of a flood, which often leads to a flushing of the coarser sediments from behind the dam. The unique linear relationship between $\alpha_{s}$ and concentration for the three instruments for the remainder of the flood suggests that after the initial peak in grain size, it remained stable. These measurements demonstrate how multi-frequency attenuation data can be used to detect changes in the grain size of suspended sediment during floods.

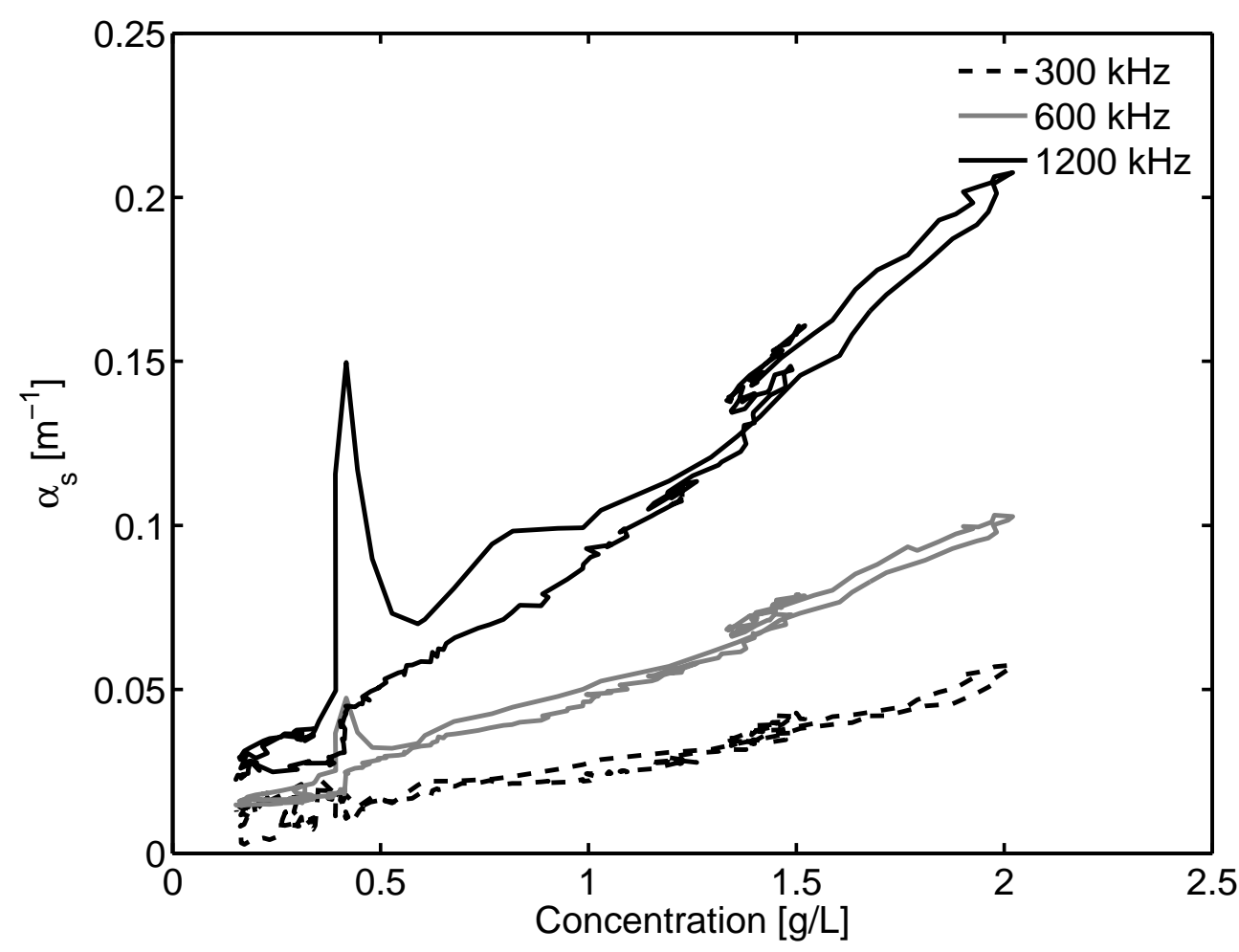

Figure 10 Sediment attenuation measured by the three H-ADCPs as a function of concentration from the turbidity meter for data collected during the flood presented in Figure 9.

\section{B. Inversion to grain size}

In the previous section it was shown that qualitative information about the evolution of the size of the suspended sediment could be obtained by examining plots of sediment attenuation versus concentration as a function of time. Figure 11 is a plot of the estimates of size 
that were obtained for Event $\mathbf{C}$ following the procedure outlined in Section IV.B. The models for viscous absorption by monosized spheres, spheres with lognormal size distributions and monosized oblate spheroids with aspect ratios of $1 / 10$ and $1 / 40$ have been tested. For all four cases, the ensemble averaged scattering attenuation coefficient is calculated using Equations 5 and 6. Looking first at the estimates for the monosized sphere model, it can be seen that most of the time $a$ was $1-2 \mu \mathrm{m}$. This is smaller than the median radius typically measured by laser diffraction in water samples collected at this study site. At the very start of the flood $a$ abruptly decreased to $0.4 \mu \mathrm{m}$, over the next hour it slowly increased to $1 \mu \mathrm{m}$, it then alternated between $40 \mu \mathrm{m}$ and $1 \mu \mathrm{m}$ for one hour. Towards the end of the falling limb of the flood, drastic fluctuations were seen again, with the estimates of $a$ alternating

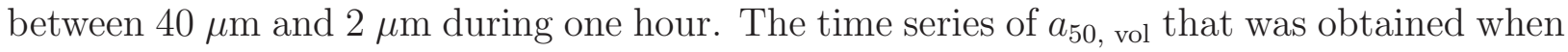
assuming lognormal size distributions was similar to that of $a$, though the peaks in size that were observed at the start and end of the event were not synchronised with the peaks in the estimates of $a$. As in the example presented in Section IV.B, the estimate of $a_{50 \text {, vol was often }}$ slightly larger than that of $a$. When the particles are assumed to be oblate spheroids with an aspect ratio of $1 / 10$, the estimates of the radius of an equal volume sphere are somewhat larger than the values obtained assuming spherical particles and they are larger still when an aspect ratio of $1 / 40$ is used. This is because the radius of an equal volume sphere is equal to $h^{-2 / 3}$ times the semi-minor axis. The time series of the estimates of size when assuming spheroidal particles are also less noisy then when assuming spherical particles, though it is difficult to discern this from Figure 11. Specifically, there are not as many spikes in the size estimates, there are only two time-steps at which sand-size particles are predicted: one at the start and the other at the end of the flood. 


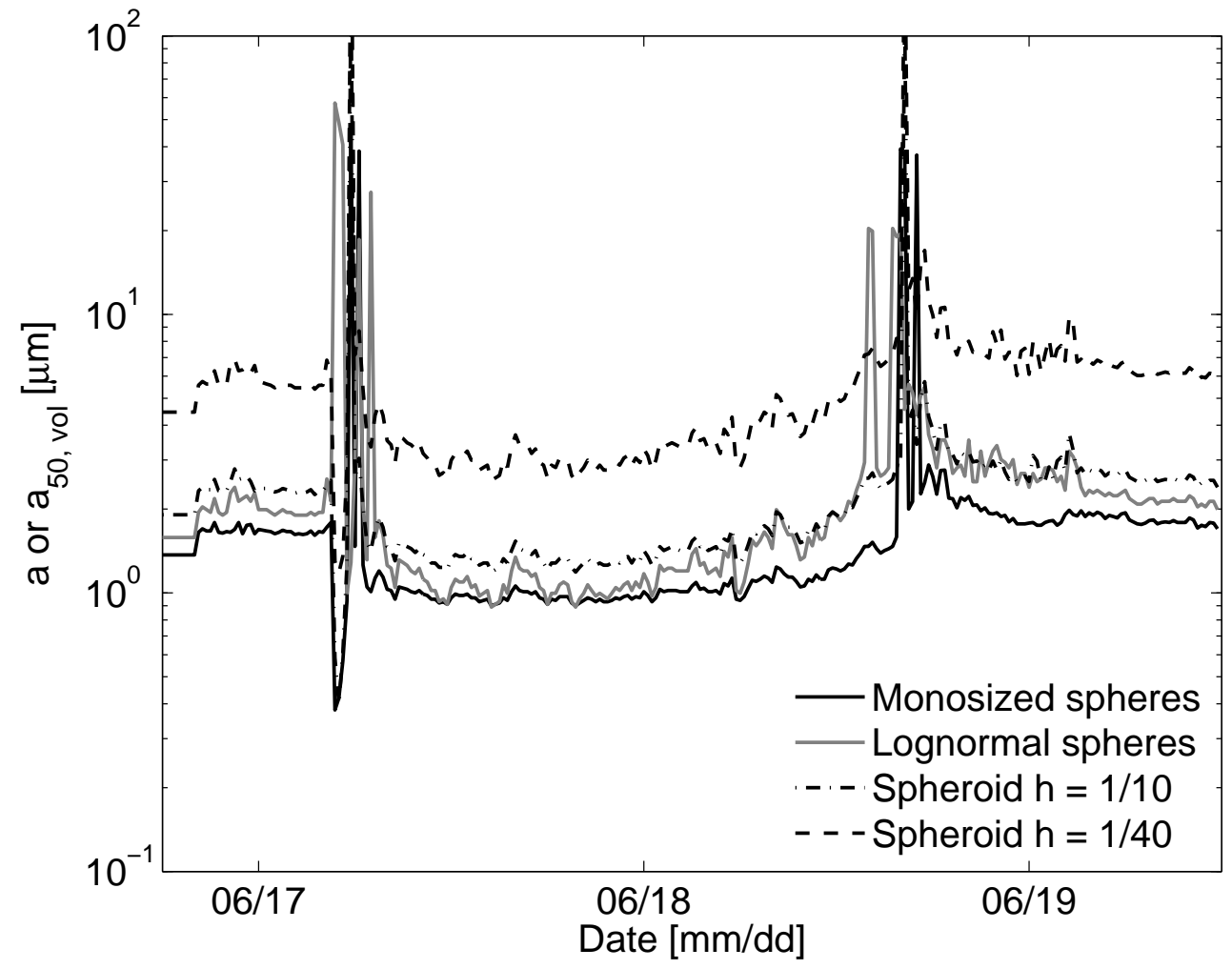

Figure 11 Estimates of particle radius obtained with multi-frequency attenuation data for Event C. For the spheroidal model the radius is that of an equal volume sphere.

Although there is a physical explanation for an increase in the size of the suspended sediment at the start of the flood, the increase in grain size that was detected on the falling limb of the flood is unexpected. We could not have predicted it based on Figure 10, nor do we have a physical explanation for it. The different timing of the peaks in the size estimates when assuming spheres of a single size or with a size distribution is due to the fact that in both cases there were often two relative minima of $\sum\left|\epsilon_{i, j}\right|$ at a given time, one around $1 \mu \mathrm{m}$, and the other around 20-30 $\mu \mathrm{m}$ for the lognormal case and around 40-50 $\mu \mathrm{m}$ for the single size case. Therefore, at a given time $\sum\left|\epsilon_{i, j}\right|$ may be a minimum at the smaller estimate of size in the single-size case, while being a minimum at the larger estimate of size in the lognormal case. This was less of a problem when the theory for oblate spheroids was used.

As stated in Section V.A the differences in the empirical values of the sediment attenuation coefficient for Events $\mathbf{A}$ and $\mathbf{B}$ implies that the size of the suspended sediment may have differed between the two events. Therefore, Figures $12(\mathrm{a}, \mathrm{b})$ are plots of the estimates of grain size for the two events using the four different models. In Figures 12(c,d) time series of concentration from the acoustic data are obtained by dividing the attenuation at 
$1200 \mathrm{kHz}$ by the theoretical sediment attenuation coefficients for the particle shapes and sizes presented in Figures 12(a,b). It can be seen that the spheroidal model with an aspect ratio of 1/10 provides the best agreement between acoustical and optical estimates of concentration for Event $\mathbf{A}$, while the spheroidal model with an aspect ratio of $1 / 40$ provides the best agreement for Event B. If the turbidity meter is assumed to be representative of the total suspended sediment concentration then the model which provides the best agreement between optical and acoustical estimates of concentration should be most indicative of the size and shape of the sediment. Therefore, it can be concluded from Figure 12 that (1) the oblate spheroidal model is more appropriate than the spherical model for both events and (2) the suspended sediment observed during Event B was more plate-like than during Event A. The results are very similar when attenuation at $300 \mathrm{kHz}$ or $600 \mathrm{kHz}$ are used and the same models also provide the best fits to the data.
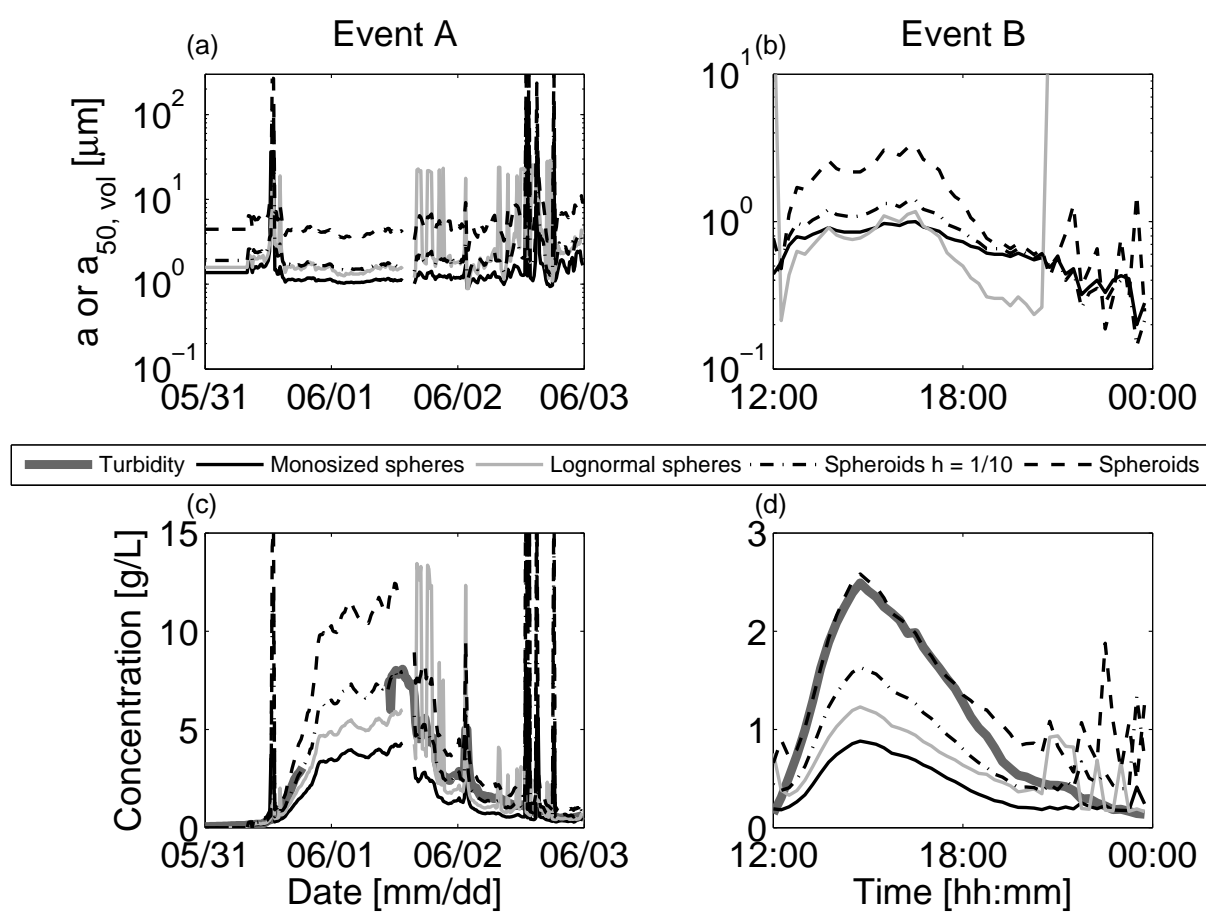

Figure 12 Multi-frequency inversion to grain size (a,b) and then to concentration (c,d) for Events $\mathbf{A}$ and $\mathbf{B}$. For the spheroidal model the radius is the radius of an equal volume sphere. The concentration estimates are obtained by dividing the attenuation observed at $1200 \mathrm{kHz}$ by the theoretical attenuation coefficients for the sizes shown in subplots $(a, b)$.

Looking at the size estimates for the model that was most appropriate for each event, it can be seen that the grain size was generally between 1 and $2 \mu \mathrm{m}$ during Event $\mathbf{A}$, but sizes of $100-120 \mu \mathrm{m}$ were predicted at the onset of the flood and on the falling limb. According 
to the multi-frequency attenuation data, the size varied steadily throughout Event $\mathbf{B}$, going from $0.5 \mu \mathrm{m}$ to $3 \mu \mathrm{m}$ and then back down again. A few small spikes in size were predicted on the falling limb of this event, but these are inconsequential compared to what was seen during Event A. There is little difference between the time-averaged size of the suspended sediment predicted for the two events, but the aspect ratios that give the best agreement between the optical and acoustical estimates of concentration differ. Thus the reason for the difference in the empirical sediment attenuation coefficients for the two events appears to be related to differences in particle shape. From Figures $12(\mathrm{c}, \mathrm{d})$ it can be seen that the concentration estimates from the multi-frequency attenuation inversion for the best-fit model generally agree very well with values from the turbidity meter, except when there are spikes in the predicted grain size. These examples show that while multi-frequency attenuation data can be used to monitor changes in grain size, there is some uncertainty in these estimates because the attenuation is not a monotonic function of size. It is clear that laboratory measurements with controlled grain size distributions are required in order to determine the accuracy of this method.

\section{DISCUSSION AND CONCLUSIONS}

Acoustic backscatter systems can be used to monitor the concentration of suspended sediment in coastal zones and in rivers since both the backscattered intensity and the sediment attenuation from a homogeneous suspension of particles depend linearly on concentration for the concentrations typically observed in the field. While the backscatter from fine sediments (silts and clays) is much weaker than that from sand, the attenuation due to fine sediments is much higher. The attenuation from fine particles (viscous attenuation) is also less sensitive to changes in grain size than is the backscattered intensity because the former depends approximately on particle radius while the latter depends on particle volume. This means that concentration estimates obtained from sediment attenuation data are more robust than those obtained from backscattered intensity data.

Measurements of sediment attenuation were obtained using intensity profiles collected with side-looking ADCPs (H-ADCPs) operating at 300, 600 and $1200 \mathrm{kHz}$ on the Isère river. A calibrated optical turbidity meter provided a continuous record of concentration. Water samples collected at various times of the year were analyzed for concentration and for grain 
size using a laboratory laser grain sizer. Empirical sediment attenuation coefficients were obtained for a flood that occurred between May 30 and June 1, 2010. They were compared to theoretical values calculated assuming spherical particles having the size distributions that were measured with the laser grain sizer in water samples collected during this flood. There was excellent agreement between theory and observations at $300 \mathrm{kHz}$, but the agreement worsened with increasing frequency. This indicates that the $300 \mathrm{kHz}$ instrument and the optical turbidity meter were equally sensitive to the particles that were in suspension at this time and that the calculation of the theoretical sediment attenuation coefficient at $300 \mathrm{kHz}$ was relatively insensitive to the uncertainties in the laser scattering size measurements. More importantly, it indicates that the spherical model may be appropriate for attenuation at $300 \mathrm{kHz}$ but is not appropriate at 600 and $1200 \mathrm{kHz}$. This last finding agrees with the laboratory measurements of Richards et al. (2003) for which it was shown that the discrepancy between the theory for spherical particles and the observations of attenuation from marine sediment particles increased with increasing frequency when the frequency exceeded $100 \mathrm{kHz}$.

The empirical sediment attenuation coefficients obtained with data from one flood were used to convert the attenuation data from two further high concentration events. For one event, the resulting concentrations were two-thirds the values from the optical turbidity meter since the empirical attenuation coefficients for this event were two-thirds the values of the first event. Despite this discrepancy, the form of the solid flood was well reproduced by the acoustic measurements. The data from the third event indicated that the grain size of the suspended sediment was not constant throughout the event. This inspired the development of a novel method for the determination of grain size using simultaneous multi-frequency attenuation data.

The sizing method consists in finding the particle size that minimizes the difference between the concentration estimates from data at multiple frequencies, where the concentration estimate at a given time is equal to the observed sediment attenuation divided by the sediment attenuation coefficient for a given grain shape and size distribution. Both a spherical and an oblate spheroidal model were tested. Using this method, it was found that the size estimates obtained when assuming mono-sized spherical particles were very close to the estimates of the median radius obtained when assuming log-normal size distributions of spheres. This is likely because the size distributions of the sediment encountered at our study site 
were relatively narrow. For this reason, the particles were assumed to be monosized when the oblate spheroid model was used in the inversion. In the absence of information about the shape of the suspended sediment at our study site, the aspect ratios that were tested were those that were used by Richards et al. (2003) in their theoretical calculations for natural marine sediments, $1 / 10$ and $1 / 40$.

Sizes obtained with the multi-frequency inversion were used to calculate theoretical attenuation coefficients and the attenuation data were divided by these values to get estimates of concentration entirely from acoustic data. The model that gave the best agreement between acoustical and optical estimates of concentration was taken to be the most appropriate model. For all events, the spheroidal model provided better agreement with the measurements than did the spherical model. This finding is consistent with the fact that the particles in suspension are predominantly silt and clay sized and are therefore more likely to be platelike than spherical. The median grain radius measured by laser diffraction in water samples collected during the flood that occurred between May 30 and June 1, 2010 was about three times larger than the acoustic estimates of size for this same event. This difference is due to the fact that optical and acoustical instruments measure different parameters. The aspect ratio that gave the best agreement between acoustical and optical estimates of concentration differed between events. The grain size also differed slightly.

In this paper we have demonstrated that measurements of acoustic attenuation at three frequencies can be used to monitor both particle size and concentration of fine sediments. However, laboratory studies with controlled grain sizes are required in order to determine the accuracy of the grain size measurements. Future field measurements at this site should include grain size measurements of the suspended sediment using a method other than laser diffraction, for example sedimentation or particle counting. It would also be useful to determine the aspect ratios of the particles in-situ to see if the values used in the multifrequency inversion are representative of the actual aspect ratios of the particles.

\section{ACKNOWLEDGEMENTS}

This work has been conducted in the framework of the Rhône Sediment Observatory project and was partly funded by the Plan Rhône. Guillaume Dramais, Mickaël Lagouy, Fabien Thollet and Laurent Dramais (Irstea) were key to the success of the field measure- 
ments and laboratory work. Stephanie Moore's PhD work was funded by the Compagnie Nationale du Rhône (CNR) and Electricité de France (EDF). We thank the CNR for the use of their instruments and data, and for the help of their employees Serge Doucet, Serge Françon, Thierry Pantel, Olivier Tisseur and especially Gilles Pierrefeu and Xavier Martin. We thank EDF for the use of their data and their employees Frédéric Gottardi, Damien Sevrez and Christian Perret for facilitating this work. We would also like to thank Teledyne RD Instruments Europe for the loan of two H-ADCPs and for their technical support throughout this project. We would like to thank the two anonymous reviewers for their very helpful reviews.

\section{References}

Ahuja, A. S. and Hendee, W. R. (1978). "Effects of particle shape and orientation on propagation of sound in suspensions", J. Acoust. Soc. Am. 63, $1074-1080$.

Braithwaite, H. (1974). "Some measurements of acoustic conditions in rivers", J. Sound. Vib. 37, $557-563$.

Crawford, A. M. and Hay, A. E. (1993). "Determining suspended sand size and concentration from multifrequency acoustic backscatter", J. Acoust. Soc. Am. 94, 3312-3324.

Downing, A., Thorne, P. D., and Vincent, C. E. (1995). "Backscattering from a suspension in the near field of a piston transducer", J. Acoust. Soc. Am 97, 1614-1620.

Fisher, F. H. and Simmons, V. P. (1977). "Sound absorption in sea water", J. Acoust. Soc. Am. $62,558-564$.

Gartner, J. W. (2004). "Estimating suspended solids concentrations from backscatter intensity measured by acoustic Doppler current profiler in San Francisco Bay, California", Marine Geology 211, $169-187$.

Gray, J. R. and Gartner, J. W. (2009). "Technological advances in suspended-sediment surrogate monitoring", Water Resources Research 45, W00D29, doi:10.1029/2008WR007063.

Guerrero, M., Szupiany, R. N., and Amsler, M. (2011b). "Comparison of acoustic backscattering techniques for suspended sediments investigation", Flow Measurement and Instrumentation 22, $392-401$.

Ha, H. K., Maa, J. P. Y., Park, K., and Kim, Y. H. (2011). "Estimation of high-resolution sediment 
concentration profiles in bottom boundary layer using pulse-coherent acoustic Doppler current profilers", Marine Geology 279, 199 - 209.

Hay, A. E. (1983). "On the remote acoustic detection of suspended sediment at long wavelengths", J. Geophys. Res. 88, 7525-7542.

Hay, A. E. (1991). "Sound scattering from a particle-laden, turbulent jet", J. Acoust. Soc. Am. 90, 2055-2074.

Hay, A. E. and Sheng, J. (1992). "Vertical profiles of suspended sand concentration and size from multifrequency acoustic backscatter", J. Geophys. Res. 97, 15661 - 15677.

Hoitink, A. J. F., Buschman, F. A., and Vermeulen, B. (2009). "Continuous measurements of discharge from a horizontal acoustic Doppler current profiler in a tidal river", Water Resour. Res. 45, W11406, doi:10.1029/2009WR0077911.

Hoitink, A. J. F. and Hoekstra, P. (2005). "Observations of suspended sediment from ADCP and OBS measurements in a mud-dominated environment", Coastal Engineering 52, 103-118.

Le Coz, J., Pierrefeu, G., and Paquier, A. (2008). "Evaluation of river discharges monitored by a fixed side-looking Doppler profiler", Water Resour. Res. 44, W00D09.

Moate, B. D. and Thorne, P. D. (2009). "Measurements and inversion of acoustic scattering from suspensions having broad size distributions", J. Acoust. Soc. Am 126, 2905-2917.

Moore, S. A. (2012). "Monitoring flow and fluxes of suspended sediment in rivers using side-looking acoustic doppler current profilers", Ph.D. thesis, Université de Grenoble.

Moore, S. A., Le Coz, J., Hurther, D., and Paquier, A. (2012). "On the application of horizontal ADCPs to suspended sediment transport surveys in rivers", Continental Shelf Research 46, 5063.

Morlock, S. E. (1996). "Evaluation of acoustic Doppler current profiler measurements of river discharge", Technical Report Water-Resources Investigations Report 95-4218, U.S. Geological Survey.

Morlock, S. E., Nguyen, H. T., and Ross, J. H. (2002). "Feasibility of acoustic Doppler velocity meters for the production of Discharge Records from U.S. Geological Survey streamflow-gaging stations", Technical Report Water-Resources Investigations Report 01-4157, U.S. Geological Survey.

Nihei, Y. and Kimizu, A. (2008). "A new monitoring system for river discharge with horizontal acoustic Doppler current profiler measurements and river flow simulation", Water Resour. Res. 
44, W00D20, doi:10.1029/2008WR006970.

Oberg, K. A. and Mueller, D. (2007). "Validation of streamflow measurements made with acoustic Doppler current profilers", Journal of Hydraulic Engineering 133, 1421 - 1432.

Rayleigh, L. (1945). Theory of Sound, volume 2, $2^{\text {nd }}$ edition (Dover, New York), 504 pp.

Richards, S. D. and Leighton, T. G. (2001). "Acoustic sensor performance in coastal waters: solid suspensions and bubbles", in 'Acoustical Oceanography' Proceedings of the Institute of Acoustics, volume 23, 399-406.

Richards, S. D., Leighton, T. G., and Brown, N. R. (2003). "Visco-inertial absorption in dilute suspensions of irregular particles", Proceedings of the Royal Society of London 459, 2153 - 2167.

Sheng, J. and Hay, A. E. (1988). "An examination of the spherical scatterer approximation in aqueous suspensions of sand", J. Acoust. Soc. Am. 83, 598-610.

Teledyne RD Instruments (2008). "Workhorse H-ADCP Operational Manual", p. 87 and p. 158.

Thorne, P. D. and Hanes, D. M. (2002). "A review of acoustic measurement of small-scale sediment processes", Cont. Shelf Res. 22, 603-632.

Thorne, P. D. and Hardcastle, P. J. (1997). "Acoustic measurements of suspended sediments in turbulent currents and comparison with in-situ samples", J. Acoust. Soc. Am. 101, 2603 - 2614.

Thorne, P. D. and Meral, R. (2008). "Formulations for the scattering properties of suspended sandy sediments for use in the application of acoustics to sediment transport processes", Cont. Shelf Res. 28, 309-317.

Thosteson, E. D. and Hanes, D. M. (1998). "A simplified method for determining sediment size and concentration from multiple frequency acoustic backscatter measurements", J. Acoust. Soc. Am 104, $820-830$.

Topping, D. J., Wright, S. A., Melis, T. S., and Rubin, D. M. (2007). "High-resolution measurements of suspended-sediment concentration and grain size in the Colorado River in Grand Canyon using a multi-frequency acoustic system", in Proc. 10th International Symposium on River Sedimentation. Moscow, Russia.

Urick, R. J. (1948). "The absorption of sound in suspensions of irregular particles", J. Acoust. Soc. Am 20, 283 - 289.

Wedd, M. W. (2003). "Determination of particle size distributions using laser diffraction", Technical Report, Educational Resources for Particle Technology, p. 1 - 4.

Wright, S. A., Topping, D. J., and Williams, C. A. (2010). "Discriminating silt-and-clay from 
suspended-sand in rivers using side-looking acoustic profilers", in Proceedings of the 2nd Joint Federal Interagency Sedimentation Conference (Las Vegas), available at the following address http://acwi.gov/sos/pubs/2ndJFIC. 
Table I The positioning of the H-ADCPs and the manufacturer specified beam width $\left(\beta_{0}\right)$, nominal maximum profiling range and distance to the far field, $r_{n}$. Depth is given with respect to the zero on the staff gauge, positive pitch indicates upward inclination and positive roll indicates that the downstream transducer faces the surface.

\begin{tabular}{lcccccc}
\hline Instrument depth pitch roll max range & $\beta_{0}$ & $r_{n}$ \\
& $(\mathrm{~m})$ & $\left(^{\circ}\right)$ & $\left({ }^{\circ}\right)$ & $(\mathrm{m})$ & $\left({ }^{\circ}\right)$ & $(\mathrm{m})$ \\
\hline $300 \mathrm{kHz}$ & -2.16 & 1.8 & 0.1 & 250 & 1 & 12.8 \\
$600 \mathrm{kHz}$ & -0.36 & -0.1 & -0.4 & 85 & 1.2 & 4.5 \\
$1200 \mathrm{kHz}$ & -0.76 & 0.1 & -0.7 & 15 & 1.5 & 2.2 \\
\hline
\end{tabular}


Table II Relevant information about the water samples for which grain size distributions are presented in Figure 6: concentration measured by filtration, percent laser obscuration for the portion of the sample used in the grain size analysis, measured median diameter and theoretical values of the ensemble averaged viscous attenuation coefficients for spherical particles having the measured distributions.

\begin{tabular}{|c|c|c|c|c|c|c|c|}
\hline Sample & $\begin{array}{c}\text { Concentration } \\
(\mathrm{g} / \mathrm{L})\end{array}$ & $\begin{array}{c}\text { Obscuration } \\
(\%)\end{array}$ & $\begin{array}{c}d_{50, \text { vol }} \\
(\mu \mathrm{m})\end{array}$ & $\begin{array}{c}d_{50, \text { num }}(\mu \mathrm{m}) \\
\left\langle\zeta_{v}\right\rangle 300 \mathrm{kHz} \\
\left(\mathrm{m}^{2} / \mathrm{kg}\right)\end{array}$ & $\begin{array}{c}\left\langle\zeta_{v}\right\rangle 600 \mathrm{kHz} \\
\left(\mathrm{m}^{2} / \mathrm{kg}\right)\end{array}$ & $\begin{array}{c}\left\langle\zeta_{v}\right\rangle 1200 \mathrm{kHz} \\
\left(\mathrm{m}^{2} / \mathrm{kg}\right)\end{array}$ \\
\hline 2010-05-11 04:31 & 0.104 & 4.9 & 10.7 & 1.1 & 0.032 & 0.053 & 0.086 \\
$2010-06-01 \quad 12: 04$ & 4.937 & 15.2 & 11.6 & 1.1 & 0.030 & 0.050 & 0.079 \\
$2010-06-03$ 15:02 & 0.200 & 8.2 & 10.7 & 1.1 & 0.031 & 0.051 & 0.081 \\
$2010-12-11$ 05:10 & 0.062 & 7.1 & 6.7 & 0.9 & 0.038 & 0.066 & 0.110 \\
\hline
\end{tabular}

